\title{
The diagnosis of epilepsy and the art of listening
}

Edwin Trevathan, MD, MPH

In this issue of Neurology, a group of epilepsy specialists report how they tested their ability to diagnose temporal lobe epilepsy (TLE) by listening to descriptions of the spells of 88 patients ("Seizure identification by clinical description in TLE: How accurate are we?"). TLE is a kind of epilepsy caused by abnormal electrical activity in the temporal area of the brain. More information about TLE can be found on the next page.

These neurologists identified 96\% of the patients with TLE by talking with their patients. Then they confirmed the diagnosis using other, more costly, tests. These tests included recording the patients' spells on videotape and using EEG (brain wave test). This study proved what all physicians know-the art of listening to patients, or obtaining a "history," is a powerful diagnostic tool.

When your neurologist asks questions about spells and listens to you speak, he or she is not just visiting with you. Your neurologist hopes that you will begin your story just before the seizure starts, then step-by-step explain the details of what you experienced. The neurologist also will want to hear the same details from any observers. As your neurologist listens, he or she compares your story to a detailed map of the brain's function. The neurologist is looking for how well the story of your spells matches this map of how an electrical seizure spreads across the brain surface. If the match is a good one, then the diagnosis of epilepsy might be made even if your EEG between seizures is normal. If the match is not good, your neurologist may decide that you do not have epilepsy.

Making a diagnosis of epilepsy based upon listening may appear simple, but it isn't. It is especially difficult for physicians who are not specialists in epilepsy. A recent study found that about one-third of patients diagnosed with epilepsy by general practitioners may not have had epilepsy at all. Learning more about how experts make the diagnosis of epilepsy may help primary care physicians make the diagnosis of epilepsy. Even the epilepsy specialists were not perfect. They diagnosed some spells as seizures that were actually not seizures at all when recorded with video and EEG. This study is important because it is among the first to carefully study the accuracy of epilepsy diagnosis by listening. There is much more to learn, however. This study only addresses the diagnosis of TLE. There are other types of epilepsy that may be difficult to diagnose. We do not know enough about the accuracy of epilepsy diagnosis among people who see a neurologist shortly after their first seizures. We also need more information on the accuracy of epilepsy diagnosis among young children.

So, what should you do to help your neurologist make the correct diagnosis? Be sure to share the details of your spells or seizures with your neurologist. This is true even if the feelings you feel or the thoughts you think at the beginning of your seizures are strange or embarrassing. Sometimes it is easier to write feelings on paper than to say them out loud. Writing down the feelings and thoughts that occur at the beginning of a seizure also helps you remember them when you need to discuss them. Your neurologist may have other suggestions on how you can tell your story with less stress. Take a relative or friend who has observed one of your seizures to the neurologist with you to help you remember the details of what you experienced. Finally, if you decide to obtain a second opinion, remember that the second neurologist will need copies of your records and will need to hear about your seizures directly from you. 


\section{www.neurology.org}

\section{What are seizures and epilepsy?}

A seizure is a sudden abnormal electrical discharge in the surface of the brain. Some seizures begin all over the brain at the same time and are called generalized seizures. Other types of seizures begin in a single place within the brain surface and are called partial seizures. How a partial seizure looks and feels depends upon where on the brain surface the seizure starts. Epilepsy is the underlying condition that causes seizures to occur in an individual patient.

\section{Temporal lobe epilepsy}

People with temporal lobe epilepsy (TLE) have seizures that come from the temporal lobe of the brain. The right and left temporal lobes contain the centers for storing memory. The temporal lobes are also centers for emotions such as fear. In most people the left temporal lobe helps control some parts of language function.

TLE is one of the most common forms of partial epilepsy. The causes in most patients are unknown. At present, there are no proven methods of prevention.

When seizures start in the temporal lobe most people have a feeling or aura. There are many different types of auras, but each patient usually has only one type of aura. This aura that signals the beginning of the seizure may be a strange, fearful feeling in the stomach or the chest. The aura may be a strange memory that seems out of place. Other people with TLE smell a bad odor as their aura.
After the aura the patient usually appears confused and cannot respond normally. While confused, the patient often has movements of the hands and mouth that appear to have no purpose. After a temporal lobe seizure, which usually lasts 90 seconds to 3 minutes, a patient is often confused and then sleeps. Often patients do not remember their temporal lobe seizures.

Young children with TLE may not be able to explain their auras. Yet parents often report that their children have a sudden look of fear, or look pale. They then stop playing, and often appear confused. They are unable to speak normally or respond normally, and they hug someone near by. After the seizure the children are sleepy and irritable.

Even though the seizures may not look bad, TLE can be very serious. Over a period of years TLE may cause memory problems. Often people with TLE feel socially isolated and depressed. Failure to completely control seizures prevents people from driving and makes it difficult to work. Adults with TLE whose seizures do not stop with treatment may have increased risk of sudden unexplained death.

\section{Diagnosis of temporal lobe epilepsy}

Most teenagers and adults with TLE have seizures that start in the middle part of the temporal lobe, which is far from the scalp. When these patients have an EEG (brain wave test), electrodes are placed on the scalp_far from where the seizures start. EEG studies between seizures in patients with temporal lobe seizures may be normal un- less a seizure occurs during the EEG test. People with TLE often have normal results on physical examinations. Neurologists rely on listening to the way seizures look and feel, in combination with EEG findings, to make the diagnosis.

An MRI is a detailed picture of the brain that may show an area of scarring (called "sclerosis") or an area of abnormally formed brain. Very few people with TLE may have an MRI that shows a tumor.

\section{Treatment of temporal lobe epilepsy}

Many people with TLE are treated successfully with medication.

About one third of people with TLE are not seizure-free, even after being treated with several different medications. If people with TLE are not seizure free after treatment with two or three medicines, medicines usually never stop the seizures. These patients should be referred to epilepsy centers with experience in epilepsy surgery. Many people with TLE who do not respond to medication become seizure-free after epilepsy surgery.

\section{For more information}

American Academy of Neurology at www.aan.com

American Academy of Neurology Foundation at www.thebrainmatters.org

Citizens United for Research in Epilepsy (CURE) at http://www.cureepilepsy.org

Epilepsy Foundation of America at www.efa.org 


\title{
Neurology
}

\section{The diagnosis of epilepsy and the art of listening}

\author{
Edwin Trevathan
}

Neurology 2003;61;E13-E14

DOI 10.1212/WNL.61.12.E13

This information is current as of December 22, 2003

\section{Updated Information \&}

Services

Permissions \& Licensing

\section{Reprints}

including high resolution figures, can be found at: http://n.neurology.org/content/61/12/E13.full

Information about reproducing this article in parts (figures,tables) or in its entirety can be found online at:

http://www.neurology.org/about/about_the_journal\#permissions

Information about ordering reprints can be found online:

http://n.neurology.org/subscribers/advertise

Neurology $®$ is the official journal of the American Academy of Neurology. Published continuously since 1951, it is now a weekly with 48 issues per year. Copyright . All rights reserved. Print ISSN: 0028-3878. Online ISSN: 1526-632X.

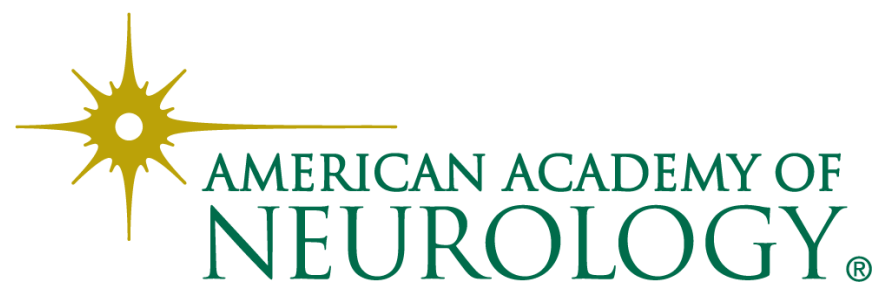

